\title{
Uso de solução de Plantago major para o controle do biofilme dental: relato de caso
}

\author{
Use of Plantago major solution for the control of dental biofilm: case report \\ Uso de solución de Plantago major para el control de biofilm dental: informe de un caso
}

Recebido: 06/01/2021 | Revisado: 07/01/2021 | Aceito: 13/01/2021 | Publicado: 15/01/2021

Jadson Araújo

ORCID: https://orcid.org/0000-0002-5608-1212 Faculdade Paulo Picanço, Brasil E-mail: jadson.araujo16@gmail.com

Máx Dobrovolski

ORCID: https://orcid.org/0000-0002-8221-0583

Centro Universitário de Pato Branco, Brasil E-mail: max_volski@hotmail.com

Vitoldo Antônio Kozlowski Júnior

ORCID: https://orcid.org/0000-0002-1339-4614

Universidade Estadual de Ponta Grossa, Brasil E-mail: vakozlowski@uepg.br

Márcia Rezende

ORCID: https://orcid.org/0000-0001-8474-5656 Faculdade Paulo Picanço, Brasil

E-mail: rezendemarcia@outlook.com

\begin{abstract}
Resumo
A inserção de fitoterápicos na forma de colutórios para uso preventivo e curativo na Odontologia é uma alternativa viável e promissora, pela facilidade de acesso e custos. A Plantago major é uma planta medicinal utilizada para inflamações bucais e orofaringe, como agente antibacteriano e antifúngico. Tem-se implementado a utilização como colutório, sendo coadjuvante dos procedimentos mecânicos de higiene oral. O objetivo foi relatar o efeito da solução aquosa de Plantago major à $7 \%$ como colutório diário, no controle do biofilme dental e gengivite. $\mathrm{O}$ paciente relatou dor nos dentes 11 e 21, e sangramento gengival durante a higienização bucal. Ao exame clínico foram observadas lesões cariosas ativas, tecido gengival edemaciado com áreas hiperemicas. Para caracterizar o quadro clínico foi aplicado o índice de manchamento dentário de Lobene, índice gengival de Löe \& Silness e o índice de placa bacteriana de Turesky. Foram detectadas áreas com manchas leves, inflamação gengival suave e moderada (sangramento sob pressão), e altos escores no índice de placa bacteriana de Turesky. Após adequação do meio bucal e profilaxia dental foi solicitado que o paciente bochechasse $10 \mathrm{~mL}$ da solução de Plantago major à $7 \%, 2$ vezes/dia, por 1 mês. Foram realizados controles clínicos semanais. Após 1 mês, foi observada ausência de manchas, redução significativa nos índices da inflamação gengival e de placa bacteriana, com ausência de sangramento. Não houveram efeitos colaterais. Concluiu-se que a solução de Plantago major apresentou perfil terapêutico efetivo no controle do biofilme dental, auxiliando no restabelecimento da saúde bucal.
\end{abstract}

Palavras-chave: Placa dentária; Plantago major; Odontologia; Fitoterapia; Agentes antimicrobianos.

\begin{abstract}
The insertion of herbal medicines in the form of mouthwashes for preventive and curative use in dentistry is a viable and promising alternative, due to the ease of access and costs. Plantago major is a medicinal plant whose leaves are used for inflammation of the mouth and oropharynx, as an antibacterial agent and antifungal agent. The use as a mouthwash has been implemented, being an adjunct to mechanical oral hygiene procedures. The objective was to report the effect of the Plantago major 7\% aqueous solution as a daily mouthwash, in the control of dental biofilm and gingivitis. The patient reported pain in teeth 11 and 21 , and gingival bleeding during oral hygiene. Clinical examination revealed active carious lesions, swollen gingival tissue with hyperemic areas. To characterize the clinical picture, the Lobene dental staining index, Löe \& Silness gingival index and Turesky plaque index were applied. Areas with light stain, mild and moderate gingival inflammation (bleeding under pressure) and high scores on the Turesky plaque index were detected. After adequacy of the oral environment and dental prophylaxis, the patient was asked to rinse $10 \mathrm{~mL}$ of the Plantago major 7\% solution, 2 times/day, for 1 month. Weekly clinical controls were performed. After 1 month, there was an absence of stains, a significant reduction in gingival inflammation and plaque rates, with no bleeding. There were no side effects. It was concluded that the Plantago major solution had an effective therapeutic profile in the control of dental biofilm, helping to restore oral health.
\end{abstract}

Keywords: Dental plaque; Plantago major; Dentistry; Phytotherapy; Antimicrobial agents. 


\begin{abstract}
Resumen
La inserción de medicamentos a base de hierbas en forma de enjuagues bucales para uso preventivo y curativo en odontología es una alternativa viable y prometedora, debido a la facilidad de acceso y costos. Plantago major es una planta medicinal utilizada para la inflamación bucal y orofaríngea, como agente antibacteriano y antifúngico. Se ha implementado el uso como enjuague bucal, siendo un complemento de los procedimientos mecánicos de higiene bucal. El objetivo fue reportar el efecto de la solución acuosa de Plantago major al 7\% como enjuague bucal diario, en el control del biofilm dental y la gingivitis. El paciente refirió dolor en los dientes 11 y 21 y sangrado gingival durante la higiene bucal. El examen clínico reveló lesiones cariosas activas, tejido gingival inflamado con áreas hiperémicas. Para caracterizar el cuadro clínico se aplicaron el índice de tinción dental de Lobene, el índice gingival de Löe \& Silness y el índice de placa de Turesky. Se detectaron áreas con manchas leves, inflamación gingival leve y moderada (sangrado bajo presión) y puntuaciones altas en el índice de placa de Turesky. Después de la adecuación del ambiente oral y la profilaxis dental, se solicitó al paciente que enjuagara $10 \mathrm{~mL}$ de la solución de Plantago major al 7\%, 2 veces al día, durante 1 mes. Se realizaron controles clínicos semanales. Después de 1 mes, hubo ausencia de tinciones, una reducción significativa de la inflamación gingival y las tasas de placa, sin sangrado. No hubo efectos secundarios. Se concluyó que la solución principal de Plantago major tenía un perfil terapéutico eficaz en el control del biofilm dental, ayudando a restaurar la salud bucal.
\end{abstract}

Palabras clave: Placa dental; Plantago major; Odontología; Fitoterapia; Antiinfecciosos.

\title{
1. Introdução
}

A importância da prevenção e da manutenção da saúde da população tem sido arduamente trabalhada. Pois um indivíduo saudável é aquele que se encontra em harmonia física, mental e social (Carvalho, Rodrigues, \& Chaves, 2008).

$\mathrm{Na}$ cavidade bucal é possível encontrar uma variada população microbiana, podendo abrigar cerca de 400 a 500 espécies (Uliana \& Briques, 2003). Microrganismos transitórios e potencialmente patogênicos podem causar doenças ou agravar as já existentes. Seus colonizadores iniciais, espécies do gênero Streptoccoccus entre outras, quando aderidos na matriz extracelular da superfície dos dentes propicia meio adequado para que outras bactérias possam ser aderidas ao biofilme dental, entre elas o S. mutans principal causador da doença cárie (Marsh, 2004). Quanto a doença periodontal destaca-se patógenos como Actinobacillus actinomycetemcomitans, Porphyromonas gingivallis e Fusobacterium nucleatum (Kim, Viana, \& ScarelCaminaga, 2007).

O biofilme dental tem sido apontado como um importante fator etiológico das doenças cárie e periodontal. Após o acúmulo por um período de 10 a 21 dias, sinais clínicos de inflamação gengival podem ser observados na maioria das pessoas (Rocha, Soares, Pereira, \& Rocha, 2008). Por isso torna-se indispensável a realização de uma higiene bucal eficaz e hábitos alimentares saudáveis, visando a diminuição destes microrganismos patogênicos (Marinho \& Araújo, 2008; Okida, Silva, Gallinari, \& Esteves, 2019; Silveira, Oliveira, \& Padilha, 2002).

Sem o controle do biofilme dental, a higiene bucal não pode ser obtida, como também a manutenção dos resultados provenientes das terapias odontológicas (Silva, Queiroz, Freitas, \& Assed, 2011). Tornando assim, o controle do biofilme indispensável para qualquer estratégia de prevenção, que pode ser executada através de meios mecânicos e químicos (Drumond, Castro, Almeida, Pereira, \& Padilha, 2004; Lima, 2009; Medeiros, 1998).

O controle mecânico do biofilme dental deve ser realizado principalmente com escova e fio dental, porém diversos fatores contribuem para que algumas pessoas não realizem uma remoção efetiva permanecendo nichos organizados de biofilme sobre a superfície dental (Gebran \& Gebert, 2002). Em virtude do exposto, se faz necessário a complementação por meios químicos, como os colutórios (Rocha et al., 2008). Entre os compostos ativos mais utilizados nos colutórios estão a clorexidina, cloreto de cetilpiridíneo e triclosan e óleos essenciais (Marinho \& Araújo, 2008; Pegoraro, Silvestri, Cara, Stefenon, \& Mozzini, 2015).

A inserção de fitoterápicos na forma de colutórios para uso preventivo e curativo na Odontologia, pode ser uma alternativa muito promissora para se alcançar sucesso clínico em determinados tratamentos, diminuir custos e facilitar a promoção de saúde, já que a utilização de plantas medicinais é de fácil aquisição e cultivo. No Brasil a fitoterapia é bem aceita 
e consolidada na medicina e cada vez mais ganha espaço na Odontologia (Francisco, 2010). Uma Política Nacional de Práticas Integrativas e Complementares foi estabelecida no SUS em 2006, sendo que em 2008 esta prática foi regulamentada para o exercício do cirurgião dentista (Cavalcante, 2010).

A Plantago major pertencente à família das Plantaginaceae é conhecida popularmente por língua de vaca, Tranchagem, Tanchagem ou Tansagem. É encontrada frequentemente nos solos do Brasil e do mundo, e é uma das várias plantas utilizadas na fitoterapia odontológica (Brasil, 2014; Trindade, Alves, Mariño, Maldaner, \& Menezes, 2018). Possui atividades farmacológicas como: anti-inflamatória, antifúngica, analgésica, antibiótica, antivirais, antileucêmica e de cicatrização de feridas (Barreto, Costa Feitosa, Araújo, Chagas, \& Costa, 2005; Brandão, Cosenza, Moreira, \& Monte-Mor, 2006; Kantawong et al., 2017; Sharma et al., 2016; Shirley, Windsor, Eckert, \& Gregory, 2017). Também é utilizada no tratamento de inflamações bucais (gengivites, periodontites e parotidites) e da orofaringe, como agente antibacteriano, antifúngico e antibiofilme (Bezerra et al., 2020; Buffon, Lima, Galarda, \& Cogo, 2001; Flores, Gamba, \& Coppola, 2009; Freitas et al., 2002; Pensantes-Sangay et al., 2020; Santos, Slusarz, Junior, \& Schwartz, 2007; Souza et al., 2020; Trindade et al., 2018). A solução de Plantago major pode ainda ser indicada para tratamento de mucosites orais em pacientes com câncer, que estejam sob tratamento de radioterapia e quimioterapia (Cabrera-Jaime et al., 2018).

Além da ampla aplicabilidade da Plantago major tem-se discutido cada vez mais a possibilidade de sua utilização como meio alternativo e economicamente viável (Anushree, Fawaz, Rao Narahari, Syed, \& JCDR, 2015; Suller \& Russell, 2000), afim de que um contingente maior da população especialmente carente, tenha acesso a um controle químico do biofilme dental, como coadjuvante dos procedimentos mecânicos de higiene oral (Navarro et al., 1998).

Assim sendo, o objetivo do presente estudo foi apresentar através de um relato de caso, o efeito da solução aquosa de Plantago major à $7 \%$ como colutório diário, no controle do biofilme dental e gengivite.

\section{Metodologia}

O presente estudo trata-se de um relato de caso, que consiste em um estudo descritivo, exploratório, com abordagem qualitativa (Pereira, Shitsuka, Parreira, \& Shitsuka, 2018). A coleta de dados foi realizada através do prontuário do voluntário, durante os procedimentos clínicos e dos registros por imagens.

O relato de caso foi iniciado somente após o voluntário concordar e assinar o Termo de Consentimento Livre e Esclarecido (TCLE), consentindo o tratamento, a divulgação das imagens e de dados coletados durante o tratamento e nas consultas de controle, seguindo os princípios éticos de pesquisa.

\section{Relato de Caso}

O paciente M.H.C., gênero masculino, 20 anos de idade, buscou tratamento odontológico tendo como queixa principal dor provocada por estímulo nos dentes 11 e 21 . Na anamnese o paciente relatou sangramento gengival durante a higienização bucal. Ao exame clínico inicial foi observado presença de lesões cariosas ativas e cavitadas, tecido gengival edemaciado e com áreas hiperemicas (Figura 1). 
Figura 1 - Aspecto clínico inicial. Vista: (A) lateral direita, (B) frontal, (C) lateral esquerda e (D) oclusal.
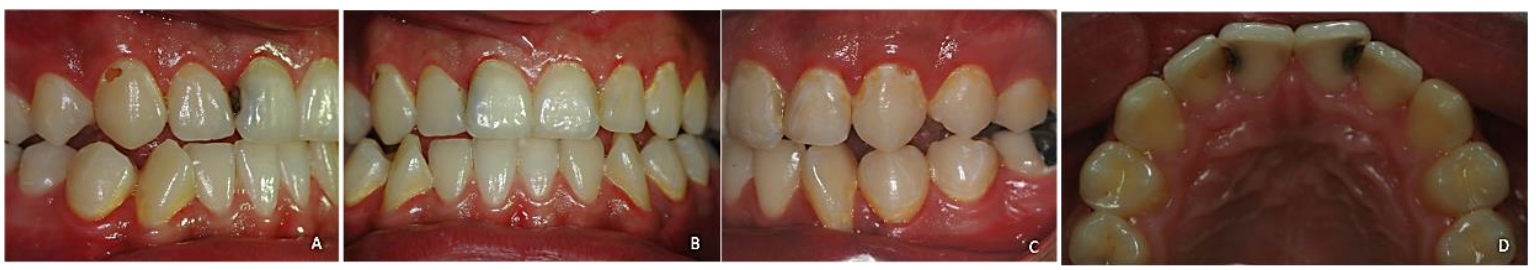

Fonte: Autores.

As lesões de cárie cavitadas, sítios de hiperemia, edema gengival e áreas de desmineralização do esmalte observados na Figura 1, evidenciam possível deficiência da remoção do biofilme na condição inicial. Lesões crônicas de cárie como as dos dentes 11 e 21 demonstram um processo de higiene oral aquém do necessário e de como afetou a condição dos tecidos de suporte dos dentes.

O paciente foi informado sobre a necessidade da realização de terapias para restabelecer a saúde bucal e também obteve instruções sobre higienização bucal. Foi explicado a importância do controle do biofilme dental e da utilização de métodos mecânicos e químicos, como escova, fio dental e colutórios. Somente após explicação dos procedimentos odontológicos, e do voluntário concordar e assinar o TCLE, o tratamento foi iniciado.

Para determinar o quadro clínico inicial foi realizada avaliação do índice de mancha de dente de Lobene (Lobene, 1979), índice de placa bacteriana de Turesky (Turesky \& Gilmore, 1970) na face vestibular de todos os dentes, e o índice gengival de Löe e Silness (Löe \& Silness, 1963). Os mesmos procedimentos foram realizados no decorrer e ao término do tratamento, como parâmetro para avaliar a efetividade do tratamento.

O índice de Lobene consiste em avaliar as manchas segundo área e severidade. A área foi avaliada através dos seguintes escores: 0 - Nenhuma mancha detectada, 1 - Mancha até 1/3 da região gengival, 2 - Mancha entre 1/3 e 2/3 da região gengival e 3 - Mancha acima de 2/3 da região gengival. E a severidade pelos escores: 0 - Ausência de mancha; 1 - Mancha leve; 2 - Mancha moderada e 3 - Mancha pesada (Lobene, 1979).

Também foram avaliadas as margens gengivais das faces vestibulares e papilas interdentais de todos os dentes pelo índice de Löe e Silness, como segue: 0 - Ausência de inflamação; 1 - Suave inflamação (Alteração desprezível de cor, textura, ausência de sangramento sob pressão); 2 - Inflamação moderada (moderado avermelhamento, edema, hipertrofia e sangramento sob pressão); 3 - Inflamação severa (acentuado avermelhamento, hipertrofia, tendência ao sangramento espontâneo e ulceração) (Löe \& Silness, 1963).

O índice Quigley-Hein modificado por Turesky foi utilizado para avaliar o acúmulo de biofilme dental nas proximidades das margens gengivais. Foi aplicado após evidenciação do biofilme dental com corante de fucsina e classificado de acordo com o seguinte escore: 0 - Nenhuma placa bacteriana; 1 - Pontos isolados ou faixa descontínua de placa; 2 - Faixa de placa fina (até $1 \mathrm{~mm}$ ) e contínua na margem gengival; 3 - Faixa maior que $1 \mathrm{~mm}$ mas cobrindo menos de 1/3 da superfície do dente; 4 - Placa cobrindo mais de 1/3, mas menos de 2/3 da superfície do dente; 5 - Placa cobrindo mais de 2/3 ou mais da superfície do dente (Turesky \& Gilmore, 1970).

O plano de tratamento eleito foi adequação do meio bucal tendo como método auxiliar na redução do biofilme o uso de solução aquosa de Plantago major a $7 \%$ manipulada em estabelecimento farmacêutico (Ervadoce Manipulação, Ponta Grossa, Paraná, Brasil). Na primeira sessão foi realizada adequação do meio bucal, para selamento temporário das lesões de cárie cavitadas. A dentina amolecida e infectada foi removida mecanicamente com o auxílio de colheres de dentina (Figura 2), seguido da inserção de cimento de ionômero de vidro convencional restaurador (FGM - Joinville, Santa Catarina, Brasil) e acabamento das restaurações provisórias com lâmina de bisturi n ${ }^{\circ} 12$ (Figura 3). Na sequência, foi realizada a orientação da 
higiene bucal ao paciente.

Figura 2 - Remoção manual da dentina infectada. (A) Aspecto inicial dos dentes 11 e 21, (B) remoção da dentina infectada com colher de dentina, (C) aspecto clínico após a remoção da dentina infectada.
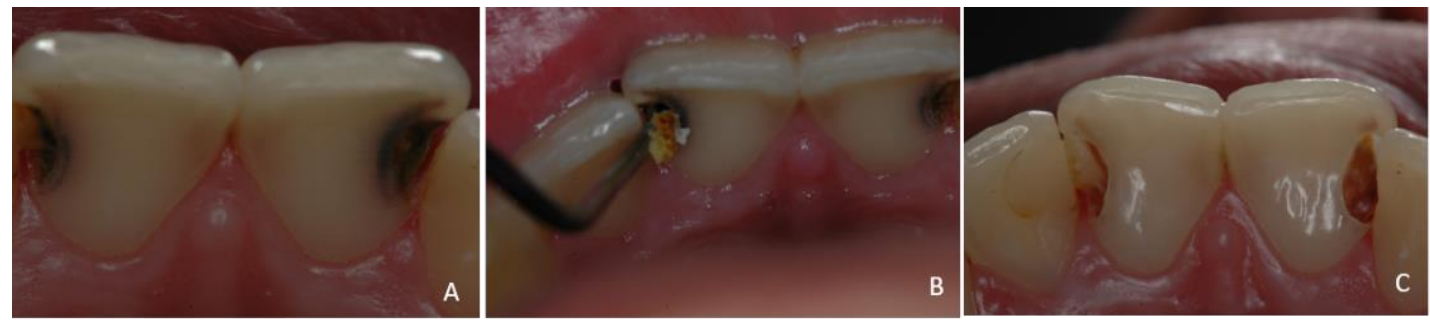

Fonte: Autores.

Após a remoção do tecido dentinário infectado verificou-se a preservação da dentina afetada, passível de remineralizarão, estando a cavidade pronta para receber o material restaurador provisório. Manter os dentes selados durante o processo de controle do biofilme dental é fundamental para reduzir fatores de retenção do biofilme (Figura 2).

Figura 3 - Adequação do meio bucal. (A) Inserção do cimento de ionômero de vidro convencional, (B) acabamento da restauração provisória com lâmina de bisturi n 12 , (C) aspecto clínico após a adequação do meio bucal.
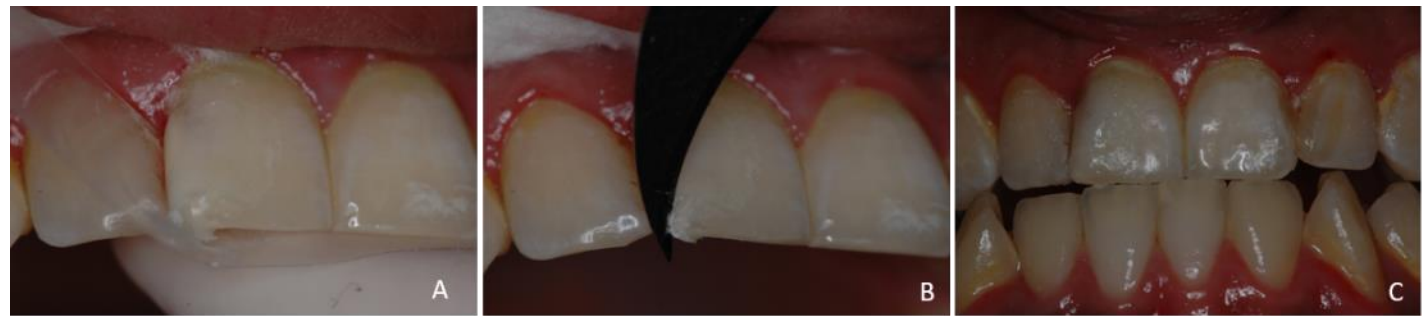

Fonte: Autores.

A utilização de tiras de matriz de poliéster auxilia na inserção do cimento de ionômero de vidro e na obtenção do contorno anatômico dos dentes. A matriz de poliéster foi pressionada contra os dentes após a inserção do cimento de ionômero de vidro, pois possibilita maior lisura superficial do material e facilita a etapa de acabamento da restauração. Posteriormente os excessos de material restaurador foram removidos com lâmina de bisturi, evitando injúria ao tecido gengival (Figura 3).

Na segunda sessão, o biofilme dental foi evidenciado com corante fucsina básica em pastilha Eviplac (Biodinâmica Ibiporã, Paraná) até a completa dissolução da pastilha (Figura 4), e mensurados os índices de mancha dental, sinais de inflamação e presença de biofilme dental. 
Figura 4 - Evidenciação do biofilme dental (2ª Sessão). Vista: (A) lateral direita, (B) frontal, (C) lateral esquerda.
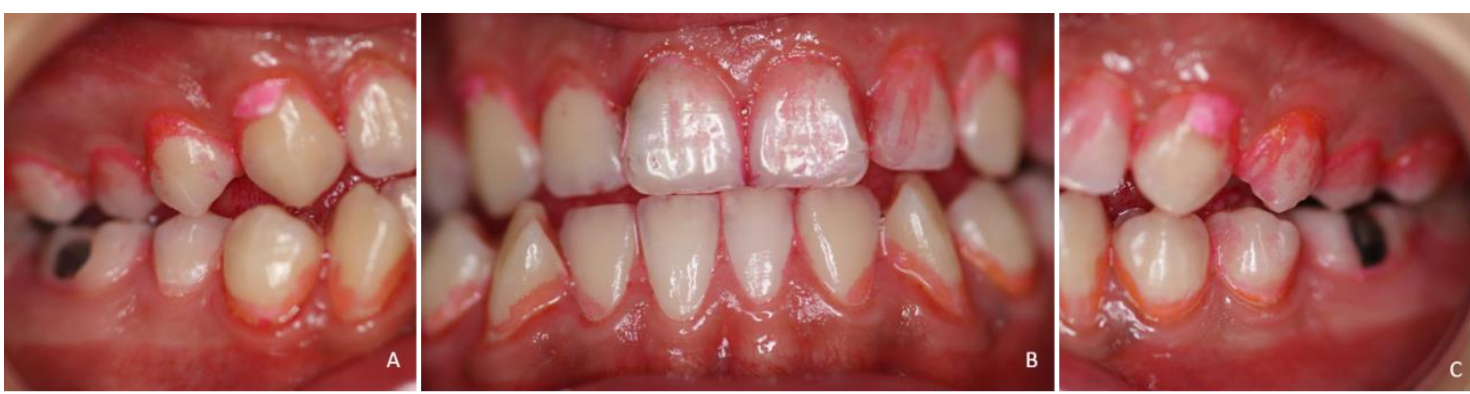

Fonte: Autores.

Pôde-se observar o acúmulo de biofilme dental crescentemente para os dentes posteriores. As faces livres também estavam recobertas por biofilme dental, como no dente 22 , demonstrando ainda falha no processo de controle do biofilme (Figura 4).

As manchas extrínsecas estavam localizadas em até $1 / 3$ da região cervical (área 1) e quanto a severidade foram classificadas em manchas leves com exceção dos dentes 17 e 24 que apresentavam manchas pesadas segundo o índice de Lobene (Lobene, 1979). Na avaliação dos tecidos moles, segundo o índice Löe e Silness (Löe \& Silness, 1963), foi detectado suave inflamação com exceção das seguintes regiões dos dentes 23, 33, 35, 36, 43 e 44, que foram classificadas como moderada, pois apresentavam sangramento sob pressão. Quanto ao índice de placa de Quigley-Hein modificado por Turesky (Turesky \& Gilmore, 1970), foi aplicado em quatro tempos: inicial, 1 semana, 2 semanas e 3 semanas. Foi atribuído score de 0 à 5 para cada dente e então estes valores foram somados.

Após, foi realizado profilaxia dental profissional com taça de borracha e pedra pomes com água em baixa rotação. Ao término do procedimento, verificou-se a eliminação das manchas e a presença de áreas de desmineralização próximo a margem gengival (Figura 5).

Figura 5 - Aspecto clínico após profilaxia profissional com taça de borracha e pedra pomes (2a Sessão).

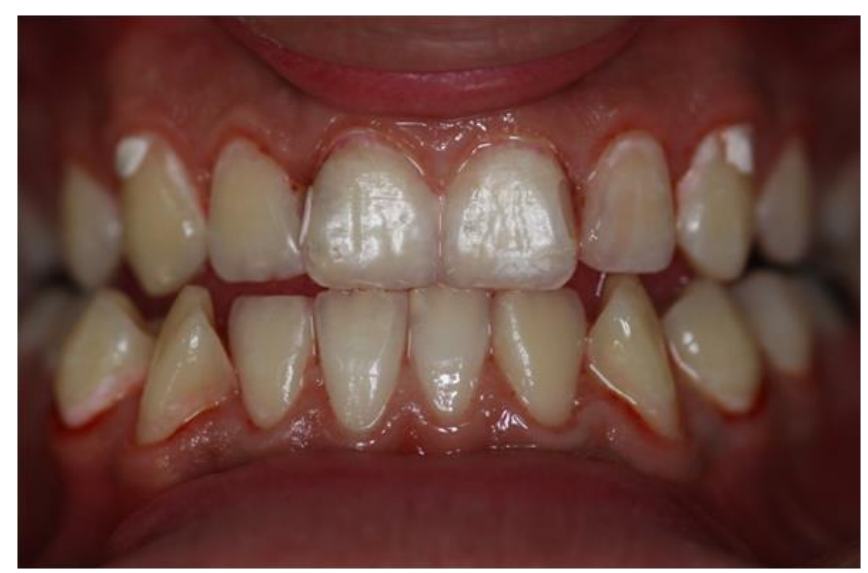

Fonte: Autores.

O paciente recebeu orientações para que bochechasse $10 \mathrm{~mL}$ da solução de Plantago major à 7\%, 2 vezes/dia, por aproximadamente 1 minuto. Nas consultas de controle semanais (terceira, quarta e quinta sessões), foi realizado a evidenciação do biofilme dental (Figuras 6, 7 e 8 ). 
Research, Society and Development, v. 10, n. 1, e29610111491, 2021

(CC BY 4.0) | ISSN 2525-3409 | DOI: http://dx.doi.org/10.33448/rsd-v10i1.11491

Figura 6 - Controle após 1 semana de uso da solução de Plantago major ( $3^{\text {a }}$ Sessão).

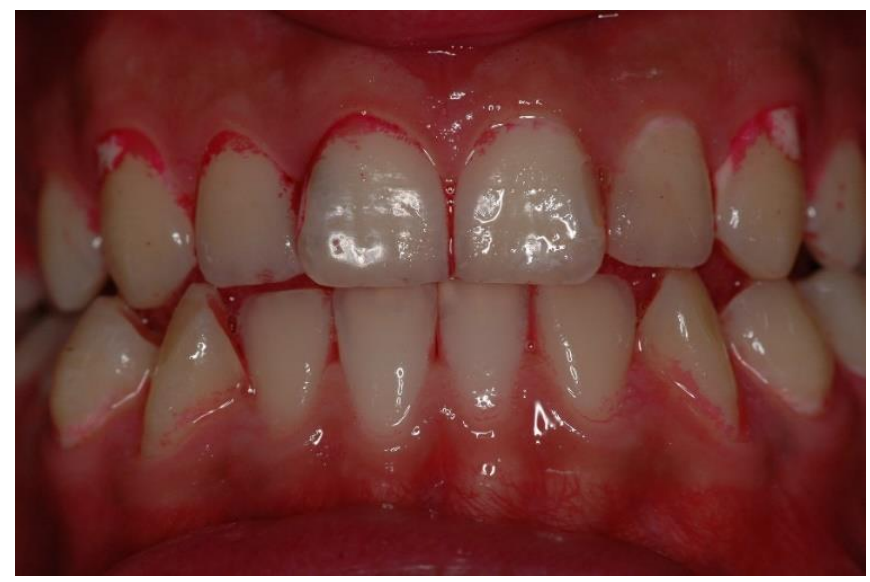

Fonte: Autores.

Figura 7 - Controle após 2 semanas de uso da solução de Plantago major (4ª Sessão).

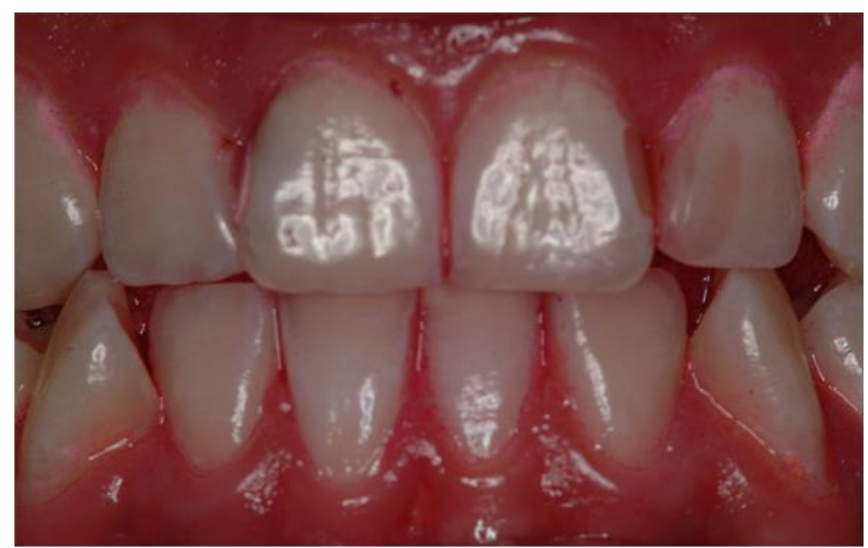

Fonte: Autores.

Figura 8 - Controle após 3 semanas de uso da solução de Plantago major (5 $5^{\text {a }}$ Sessão).

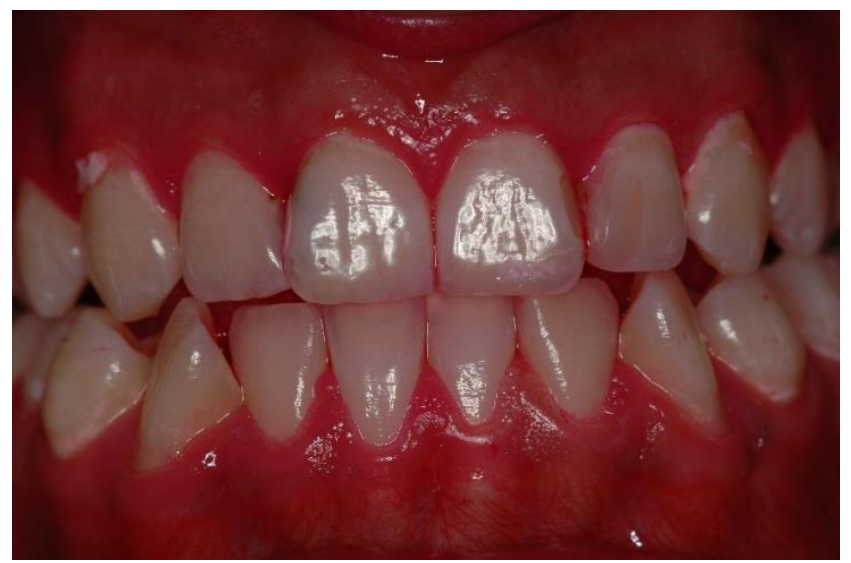

Fonte: Autores.

Observou-se um decréscimo do biofilme dental ao longo das semanas (Figuras 6, 7 e 8), e na terceira sessão, o paciente relatou que a dor dental havia cessado.

Após a classificação do biofilme dental, de acordo com os escores de 0 a 5 (Turesky \& Gilmore, 1970), descritos anteriormente, realizou-se a média final. Os escores foram somados e divididos pelo número de faces avaliadas, encontrando- 
se a média final, ou seja, o Índice de Turesky (Tabela 1). Quanto menor o acúmulo de biofilme dental na região cervical, menor é o índice encontrado, o qual permite avaliar a intensidade do biofilme na região cervical.

Tabela 1 - Índice de placa (Quigley-Hein modificado por Turesky) calculado para medidas avaliadas nos períodos inicial, 1 semana, 2 semanas e 3 semanas.

\begin{tabular}{lcccc}
\hline & \multicolumn{4}{c}{ PERÍODOS } \\
\cline { 2 - 5 } & INICIAL & 1 SEMANA & 2 SEMANAS & 3 SEMANAS \\
\hline Índice de Turesky & 3,75 & 1,85 & 1,5 & 0,25 \\
\hline
\end{tabular}

Fonte: Autores.

Os valores do Índice de Turesky apresentados na Tabela 1, demonstram uma melhora no controle do biofilme dental com a implementação do tratamento proposto. O paciente continuou usando o fitoterápico através de bochechos diários por mais uma semana, e então realizada a avaliação final (Figura 9), totalizando 1 mês de uso da solução de Plantago major.

Figura 9 - Controle após 4 semanas de uso da solução de Plantago major (6 ${ }^{\text {a }}$ Sessão). (A) Antes e (B) após evidenciação do biofilme dental.
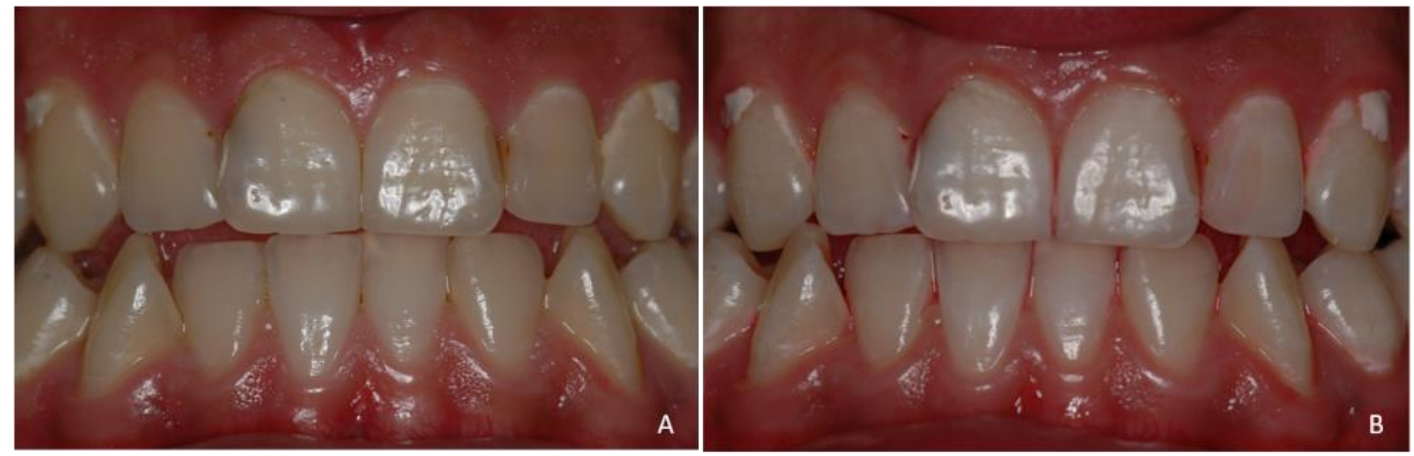

Fonte: Autores.

Na avaliação final, observou-se a ausência de manchas (Figura 9), redução significativa nos índices de inflamação gengival e de biofilme dental, e ausência de sangramento gengival. Não houveram efeitos colaterais durante a utilização da solução de Plantago major. Após iniciou-se o tratamento restaurador. 


\section{Discussão}

Quando a saúde bucal está comprometida devido a presença de lesões cariosas e doença periodontal é indispensável devolver ao paciente o padrão ecológico do meio bucal, através de procedimentos que controlem a colonização microbiana e reduzam fatores retentivos de biofilme dental (Okida et al., 2019).

No presente relato de caso optou-se por realizar adequação do meio bucal previamente ao tratamento restaurador, para evitar a manutenção da doença e ciclos restauradores repetitivos (Silveira et al., 2002). Além disso, a presença de lesões cariosas cavitadas propiciam maior retenção de biofilme dental e um maior número de colônias microbianas (Medeiros, 1998), por isso as restaurações provisórias devem ser realizadas por ser um procedimento importante para redução da atividade cariogênica, enquanto são instituídas medidas preventivas de controle (Silva et al., 2011).

O cimento de ionômero de vidro foi o material eleito para o selamento provisório das lesões cariosas devido a ação remineralizadora da dentina afetada, pelas propriedades de adesão à estrutura dental, liberação de flúor, paralisação do processo carioso e pelo baixo custo (Silva, Queiroz, Freitas, \& Assed, 2011).

Na sequência, seguindo o tratamento proposto para o controle do biofilme dental, foi utilizada a solução de Plantago major. A utilização de agentes químicos para o controle do biofilme dental (Medeiros, 1998; Okida et al., 2019), tem sido indicado principalmente para pacientes que apresentam dificuldade de higienização bucal e com alto risco a cárie (Drumond et al., 2004). Estes agentes podem estar presentes em dentifrícios ou soluções para bochechos, os quais tem sido alvo de muitos estudos, pois o controle do biofilme dental é indispensável para a manutenção da saúde bucal (Lima, 2009).

Para seleção do agente químico, alguns pontos devem ser considerados, como: grau de higiene do paciente, características farmacológicas e efeitos adversos do medicamento, custo e aceitação do paciente (Gebran \& Gebert, 2002).

Optou-se pela utilização da solução de Plantago major por ter custo acessível e apresentar importante perfil terapêutico no tratamento das desordens bucais e no controle do biofilme dental (Souza et al., 2020). A Plantago major, possui em sua composição fitoquímica o tanino, que atua como inibidor enzimático, e contribui para a ação cicatrizante, antimicrobiana e anti-inflamatória, e também possui mucilagens que funcionam como anti-inflamatório, cicatrizante e protetor das mucosas (Buffon et al., 2001). São esses componentes que atuam em bactérias pertencentes ao biofilme cariogênico, como S. mutans (Bezerra et al., 2020; Buffon et al., 2001). Sua atividade antibacteriana tem despertado muito interesse na comunidade científica, ação esta que possivelmente esteja relacionada à presença de taninos e flavonóides (Trindade et al., 2018). Também possui em sua composição aucubina (iridóides glicosídeo) e baicaleína (flavonóide) (Shirley et al., 2017). A aucubina está relacionada ao efeito cicatrizante e anti-inflamatório e a baicaleína aos efeitos antioxidantes, antimicrobianos, anti-inflamatórios e antifúngico (Cao et al., 2008; Cheng et al., 2012; Shim, Choi, Jeong, \& Kang, 2007). Pesquisas demonstram a efetividade da Plantago major sobre a Candida albicans devido à presença desses componentes. A Candida albicans, é um fungo que pode estar presente no biofilme dental e causar uma variedade de infecções na cavidade bucal (Shirley et al., 2017).

No estudo de Anushree et al. (2015) verificou-se que a eficácia de um dentifrício contendo Plantago major contra S. mutans foi similar ao triclosan. Esses resultados promissores tem estimulado pesquisas com plantas terapêuticas, pois medicamentos como o triclosan e antibióticos podem gerar resistência dos microrganismos (Anushree et al., 2015; Suller \& Russell, 2000).

A eficácia antimicrobiana da Plantago major foi avaliada frente a microrganismos causadores de endocardite bacteriana, enfermidade que pode estar relacionada com a prática odontológica. Verificou-se ação semelhante da planta com a clorexidina, tanto para a K. pneumoniae quanto para a C. tropicalis (Santos et al., 2007). Outros pesquisadores também verificaram a atividade antibacteriana da Plantago major para as cepas de S. aureus e P. aeruginosa, havendo redução da 
densidade ou inibição do crescimento bacteriano (Trindade et al., 2018). Efeitos significativos foram verificados contra a P. gingivalis (Buffon et al., 2001; Freitas et al., 2002; Pensantes-Sangay et al., 2020; Valverde \& Carolina, 2017), bactéria conhecida por estar associada a doença periodontal (Bezerra et al., 2020). Contudo a literatura não é unânime, estudo como o de Sharma et al. (2016) não verificaram efetividade da Plantago major frente a P. gingivalis. Essas variações podem ocorrer devido aos métodos extrativos e solventes empregados, fato que pode estar relacionado aos diferentes metabólitos extraídos e consequentemente interferindo na eficácia (Trindade et al., 2018).

Há relatos de que a Plantago major é uma das plantas utilizadas em medicina natural popular e seu desempenho quanto ao tratamento de afecções e processos inflamatórios é comprovado (Barreto et al., 2005; Brandão et al., 2006). Contudo, um estudo etnobotânico realizado com 62 raizeiros e 197 dentistas em 6 municípios brasileiros, foi observado que a Plantago major não estava descrita entre as plantas medicinais mais utilizadas. Concluiu-se também que as indicações mais referenciadas para os fitoterápicos quanto ao uso odontológico diziam respeito a inflamações, infecções, odontalgias, cicatrizações, halitose e hemostasia. Percebe-se que o controle do biofilme em si é um tema ainda pouco referido (Cavalcante, 2010).

No presente estudo, os excelentes resultados obtidos ao término do tratamento proposto para o controle do biofilme dental, deve-se a associação de diferentes estratégias utilizadas. Vale ressaltar, que o controle químico não deve substituir o controle mecânico executado pelo paciente e profissional, sendo indispensável a motivação do paciente, tornando-o um cooperador consciente (Gebran \& Gebert, 2002).

Não houve efeitos adversos associados a utilização da Plantago major durante todo o período de uso (1 mês). Isso não seria possível se o paciente estivesse fazendo uso de uma substância como a Clorexidina, mesmo na concentração recomendada de $0,12 \%$ para o controle do biofilme dental. Isso porque ela apresenta efeitos colaterais conhecidos amplamente, como o manchamento dos dentes, alterações de paladar e lesões escamativas e ulcerações na mucosa bucal (Pegoraro et al., 2015).

Quanto a toxicidade, González, Coto Morales, Soto Rodríguez, and Pazos (2003) administraram Plantago major diariamente para ratos, durante cinco dias, por um período de 40 dias e concluíram que o extrato não causou irritação significativa durante o período de observação. Nazarizadeh, Mikaili, Moloudizargari, Aghajanshakeri, e Javaherypour (2013) observaram que o extrato da folha é confiável e não tóxico, com forte ação hepatoprotetora. Contudo, é necessário o desenvolvimento de novas pesquisas devido divergências de estudos na literatura, a fim de esclarecer se a planta pode apresentar interações medicamentosas e efeitos colaterais (Bezerra et al., 2020).

\section{Considerações Finais}

O uso da solução aquosa de Plantago major apresentou perfil terapêutico efetivo no controle do biofilme dental, auxiliando no restabelecimento da saúde bucal. Contribuiu para redução nos índices de placa, mancha e sinais de inflamação em tecidos moles. Os procedimentos clínicos realizados e os resultados obtidos demonstraram a viabilidade da inclusão da Plantago major para o controle de biofilme dental. Apesar de ser um relato único, pôde-se identificar melhora clínica suficiente para restabelecer saúde gengival e propiciar ambiente favorável para receber o tratamento restaurador.

Sugere-se a realização de mais pesquisas para comprovar a efetividade da solução de Plantago major em diferentes concentrações, métodos extrativos e solventes empregados. Há necessidade de ser avaliado a toxicidade, os efeitos colaterais e as possíveis interações medicamentosas em períodos mais longos de utilização do medicamento fitoterápico. 


\section{Referências}

Anushree, B., Fawaz, M. A., Rao Narahari, T. S., Syed, A. J. J. O. C., \& JCDR, D. R. (2015). Comparison of antimicrobial efficacy of triclosan-containing, herbal and homeopathy toothpastes-an invitro study. Journal of Clinical and Diagnostic Research, 9(10), DC05-DC08. https://doi.org/10.7860/JCDR/2015/11984.6626

Barreto, L., Costa Feitosa, M., Araújo, J. d., Chagas, K., \& Costa, K. J. A. E. O. (2005). Acción antimicrobiana in vitro de dentífricos conteniendo fitoterápicos. Avances en odontoestomatologia, 21(4), 195-201.

Bezerra, M. S., Bezerra, A. S., Mendes, T. A. D., Brum, N. F., de Souza, G. S., Marquezan, P. K. J. R. (2020). Atividade antimicrobiana e antibiofilme da Plantago major: uma revisão de literatura. Research, Society, \& Development, 9(9), e496997495-e496997495. http://dx.doi.org/10.33448/rsd-v9i9.7495

Brandão, M. G. L., Cosenza, G. P., Moreira, R. A., \& Monte-Mor, R. L. J. R. B. d. F. (2006). Medicinal plants and other botanical products from the Brazilian Official Pharmacopoeia. Revista Brasileira de Farmacognosia. 16(3), 408-420. https:// doi. org/10.1590/S0102-695X2006000300020

Brasil. (2014). Monografia da espécie Plantago major L. (tanchagem). Brasília: Ministério Da Saúde, 5, 78.

Buffon, M. D. C. M., Lima, M. L. D. C., Galarda, I., \& Cogo, L. J. V. A. (2001). Avaliação da eficácia dos extratos de Malva sylvestris, Calêndula officinalis, Plantago major e Curcuma zedoarea no controle do crescimento das bactérias da placa dentária. Estudo in vitro. Visão Acadêmica, 2(1). https://doi.org/10.5380/acd.v2i1.485.

Cabrera-Jaime, S., Martínez, C., Ferro-García, T., Giner-Boya, P., Icart-Isern, T., Estrada-Masllorens, J. M., \& Fernández-Ortega, P. J. E. J. O. O. N. (2018). Efficacy of Plantago major, chlorhexidine $0.12 \%$ and sodium bicarbonate $5 \%$ solution in the treatment of oral mucositis in cancer patients with solid tumour: A feasibility randomised triple-blind phase III clinical trial. European Journal of Oncology Nursing, 32, 40-47. https://doi.org/10.1016/j.ejon.2017.11.006

Cao, Y., Dai, B., Wang, Y., Huang, S., Xu, Y., Cao, Y., Gao, P., Zhu, Z., \& Jiang, Y. (2008). In vitro activity of baicalein against Candida albicans biofilms. International journal of antimicrobial agents, 32(1), 73-77. 10.1016/j.ijantimicag.2008.01.026.

Carvalho, M. F. D., Rodrigues, P. A., \& Chaves, M. D. G. A. M. (2008). Halitose: revisão literária. HU rev, $273-279$.

Cavalcante, A. L. F. D. A. (2010). Plantas medicinais e saúde bucal: estudo etnobotânico, atividade antimicrobiana e potencial para interação medicamentosa. Dissertação (Mestrado em Odontologia), Universidade Federal da Paraíba, João Pessoa.

Cheng, Y. H., Li, L. A., Lin, P., Cheng, L. C., Hung, C. H., Chang, N. W., \& Lin, C. (2012). Baicalein induces G1 arrest in oral cancer cells by enhancing the degradation of cyclin D1 and activating AhR to decrease Rb phosphorylation. Toxicology and applied pharmacology, 263(3), 360-367. https://doi.org/10.1016/j.taap.2012.07.010

Drumond, M. R. S., Castro, R. D. D., Almeida, R. V. D. D., Pereira, M. D. S. V., \& Padilha, W. W. N. (2004). Estudo comparativo in vitro da atividade antibacteriana de. Pesqui. bras. odontopediatria clín. integr, 33-38.

Flores, I. L., Gamba, T. D. O., \& Coppola, M. (2009). Perspectivas do uso de espécie vegetal do gênero Plantago como antiinflamatório. XI ENPOS I Mostra Científica, 1-4.

Francisco, K. S. F. (2010). Fitoterapia: uma opção para o tratamento odontológico. Revista Saúde, 4(1), 18-24.

Freitas, A. G., Costa, V., Farias, E. T., Lima, M. C. A., Sousa, I. A., \& Ximenes, E. A. (2002). Atividade antiestafilocócica do Plantago major L. Revista Brasileira de Farmacognosia, 12, 64-65.

Gebran, M. P., \& Gebert, A. P. O. (2002). Controle químico e mecânico de placa bacteriana. Tuiuti: Ciência e Cultura, 26(3), 45-58.

González, M. G., Coto Morales, T., Soto Rodríguez, G. A., \& Pazos, L. (2003). [Sub-chronic toxicity and test of eye irritability of leaf aqueous extract from Plantago major (plantaginaceae)]. Rev Biol Trop, 51(3-4), 635-638.

Kantawong, F., Singhatong, S., Srilamay, A., Boonyuen, K., Mooti, N., Wanachantararak, P., \& Kuboki, T. (2017). Properties of macerated herbal oil. Bioimpacts, 7(1), 13-23. doi:10.15171/bi.2017.03

Kim, Y. J., Viana, A. C., \& Scarel-Caminaga, R. M. J. R. D. O. D. U. (2007). Influência de fatores genéticos na etiopatogênese da doença periodontal. Revista de Odontologia da UNESP, 36(2), 175-180.

Lima, J. E. D. O. (2009). Programa preventivo da cárie dentária baseado no controle mecânico da placa bacteriana em crianças, por meio da profilaxia profissional periódica: Resultados após 25 anos de acompanhamento. Revista Dental Press de Ortodontia e Ortopedia Facial, 14(3), 44-51.

Lobene, R. R. (1979). Clinical studies of plaque control agents: an overview. Journal of Dental Research, 58(12), $2381-2388$.

Löe, H., \& Silness, J. (1963). Periodontal disease in pregnancy I. Prevalence and severity. Acta odontologica scandinavica, 21(6), 533-551.

Marinho, B. V. S., \& Araújo, A. C. (2008). Uso dos enxaguatórios bucais sobre a gengivite e biofilme dental/Use mouthwash in gingivitis and dental biofilm. IJD. International Journal of Dentistry, 6(4), 124-131.

Marsh, P. D. (2004). Dental plaque as a microbial biofilm. Caries research, 38(3), 204-211.

Medeiros, U. J. G. J., Namen FM. (1998). Controle da doença cárie. In: Galan J, Namen FM. Dentística restauradora. O essencial para o clínico. São Paulo: Santos, 8-47.

Navarro, D. D. F., dos Santos, E. A. T., da Rocha, J. C. F., Bremm, L. L., Jukoski, M., Ribeiro, P. G., \& Kozlowski Jr, V. A. (1998). Effect of chlorhexidine digluconate, Plantago major and placebo mouth rinse on dental plaque and gingivitis. Revista Brasileira de Plantas Medicinais, 1(1), $28-38$. 
Nazarizadeh, A., Mikaili, P., Moloudizargari, M., Aghajanshakeri, S., \& Javaherypour, S. (2013). Therapeutic uses and pharmacological properties of Plantago major L. and its active constituents. J Basic Appl Sci Res, 3(9), 212-221.

Okida, R. C., Silva, H. M. D., Gallinari, M. D. O., \& Esteves, L. M. B. (2019). Adequação do meio bucal para restaurações estéticas: relato de caso. Rev Odontol. Araçatuba (Impr.), 28-33.

Pegoraro, J., Silvestri, L., Cara, G., Stefenon, L., \& Mozzini, C. B. (2015). Efeitos adversos do gluconato de clorexidina à 0, 12\%. Journal of Oral Investigations, 3(1), 33-37.

Pensantes-Sangay, S. J., Calla-Poma, R. D., Requena-Mendizabal, M. F., Alvino-Vales, M. I., \& Millones-Gómez, P. A. (2020). Chemical Composition and Antibacterial Effect of Plantago Major Extract on Periodontal Pathogens. Pesquisa Brasileira Em Odontopediatria e Clínica Integrada, $20,1-10$. https://doi.org/10.1590/pboci.2020.100

Pereira A.S. et al. (2018). Metodologia da pesquisa científica. UAB/NTE/UFSM.

Rocha, A. R. A., Soares, C. L., da Silva Pereira, S. L., \& Rocha, M. M. N. P. (2008). Efeito de diferentes agentes químicos sobre microrganismos de biofilme supragengival: estudo experimental in vitro. UFES revista de odontologia, 10(2), 27-30.

Santos, E. B., Slusarz, P. A., Kozlowski Junior, V. A., \& Schwartz, J. P. (2007). Eficácia antimicrobiana de produtos naturais frente a microrganismos causadores da endocardite bacteriana. Publicatio UEPG: Ciências Biológicas e da Saúde, 13, 67-72.

Sharma, H., Yunus, G. Y., Mohapatra, A. K., Kulshrestha, R., Agrawal, R., \& Kalra, M. (2016). Antimicrobial efficacy of three medicinal plants Glycyrrhiza glabra, Ficus religiosa, and Plantago major on inhibiting primary plaque colonizers and periodontal pathogens: An in vitro study. Indian Journal of Dental Research, 27(2), 200-204. https://doi.org/10.4103/0970-9290.183135

Shim, K. M., Choi, S. H., Jeong, M. J., \& Kang, S. S. (2007). Effects of aucubin on the healing of oral wounds. in vivo, 21(6), 1037-1041.

Shirley, K. P., Windsor, L. J., Eckert, G. J., \& Gregory, R. L. (2017). In Vitro Effects of Plantago Major Extract, Aucubin, and Baicalein on Candida albicans Biofilm Formation, Metabolic Activity, and Cell Surface Hydrophobicity. Journal of Prosthodontics, 26(6), 508-515. https://doi.org/10.1111/jopr.12411

Silva, F. W. G. D. P., Queiroz, A. M. D., Freitas, A. C. D., \& Assed, S. (2011). Utilização do ionômero de vidro em odontopediatria. Odontologia ClínicoCientífica (Online), 10(1), 13-17.

Silveira, J. L. G. C. D., Oliveira, V. D., \& Padilha, W. W. N. (2002). Avaliação da redução do índice de placa visível e do índice de sangramento gengival em uma prática de promoção de saúde bucal com crianças. Pesquisa Odontológica Brasileira, 16(2), 169-174.

Souza, A. C. d. A., Esmerino, L. A., Harms, N. M., Tardivo, R. C., \& Kozlowski Junior, V. A. (2020). Análise da sensibilidade antimicrobiana de espécies de plantago frente a microrganismos de relevância no tratamento de desordens bucais. In: Condições teórico-práticas das ciências da saúde no Brasil, 10-23. 10.22533/at.ed. 4232004123

Suller, M. T. E., \& Russell, A. D. (2000). Triclosan and antibiotic resistance in Staphylococcus aureus. Journal of Antimicrobial Chemotherapy, 46(1), 11-18.

Trindade, G. O., Alves, V. H., Mariño, P. A., Maldaner, G., \& Menezes, A. P. S. (2018). Triagem fitoquímica e avaliação do potencial antibacteriano de extratos das folhas de Plantago major L. Revista de Iniciação Científica da Universidade Vale do Rio Verde, 9(1).

Turesky, S., \& Gilmore, G. J. J. P. (1970). Reduced plaque formation by chloromethyl analogue of Vit. C., J Periodontol, 41(1), 41-43. DOI: 10.1902/jop.1970.41.41.41

Uliana, R., \& Briques, W. (2003). Halitose-Conceitos básicos sobre diagnóstico, microbiologia, causa, tratamento. Anais do $15^{\circ}$ Conclave Odontológico Internacional de Campinas, 1678-99.

Valverde, B., Carolina, V. (2017). Efecto inhibitorio del extracto de manzanilla (Matricaria Chamomilla), extracto de llantén (Plantágo major 1.) y la combinación del extracto de manzanilla y llantén comparado con la clorhexidina sobre cepa de Porphyromona gingivalis. Trabalho de Conclusão de Curso. Quito: UCE. 